general, the contributions are authoritative and well written, and each is followed by an extensive list of references. The book is well illustrated and excellently produced, and there is a good index of 43 pages. Quite apart from genetical libraries, for which this book is, of course, an absolute essential, it is difficult to see what biological or medical laboratory could afford to be without a copy. As a work of reference, it is clearly invaluable, and at least one person not unfamiliar with the mouse has made several interesting discoveries in thumbing through this volume.

H. GRÜNEBERG

\section{CONNECTIVE TISSUE ENDOCRINOLOGY}

\section{Hormones and Connective Tissue}

Edited by Gustav Asboe-Hansen. (Scandinavian University Books.) Pp. 431. (Copenhagen: Ejnar Munksgaard, 1966.) 103 D.kr.

Dr. AsBoe-HANSEN is at the centre of a team of physicians, surgeons, anatomists and dermatologists who join together in a unique experiment in collaborative research on connective tissue motabolism. In 1954 he edited a group of papers Connective Tissue in Health and Disease which introduced the work of the group, but which by the inclusion of reviews by other experts provided a volume holding within its covers all the growing points of a rapidly expanding subject. During the intervening thirteen years, connective tissue studies have advanced quickly, and Dr. Asboe-Hansen's present volume demonstrates not only the quantitative development in Copenhagen but also the change in emphasis there. The broad coverage of the earlier volume has been replaced by the treatment in depth of a single aspect.

The seventeen chapters cover a variety of aspects of connective tissue endocrinology. The first two deal with the effects of a broad spectrum of hormones on tissue mucopolysaccharides and on the formed elements of blood. Another seven chapters deal with the specific effects of individual hormones on selected tissues, whereas a further group is concerned with more clinical aspects of connective tissue metabolism.

During the past decade, considerable evidence has been provided from which the primary and secondary structure of the collagen fibre has been deduced. It might appear surprising, therefore, that a book of this calibre fails to include any correlation between chemical structure and function and a discussion as to show this is determined by environmental and especially by hormonal influences.

Unfortunately metabolic studies on connective tissue components have not kept pace with structural studies, and research in the first of these fields is still very much at the observational level. Many of the contributions to the present book, therefore, consist of experimental observations which appear to have little relationship with one another. Such a compilation does not lend itself to easy reading. It is not a book to be read at bed-time, but the solid meat between its covers should be a useful source of information for those wishing to learn how individual hormones may affect the tissues in which they are interested.

If one has to make any criticism of the subject matter of the book, it has one fault in common with any publica. tion originating in a single institute or group of workers. Because of the circumscribed nature of the work undertaken by the various collaborators, their approach is uniform. A large proportion of the references quoted are Scandinavian and the work of one or two other schools engaged in similar studies is virtually ignored. If, however, the volume is accepted for what it is--a survey of the work of a highly active and energetic research group in relation to selected studies elsewhere- it should prove to be of great use to other workers in the field.

As is usual with volumes from Munksgaard, the book is well produced. It might, however, have benefited from an author index.

D. A. Hall

\section{Problems in Mathematical Physics}

By N. N. Lebedev, I. P. Skal'Skaya and Ya. S. Uflyand. Translated by A. R. M. Robson. Translation edited by J. Reinfelds. (International Series of Monographs in Pure and Applied Mathematics, Vol. 84.) Pp. viii +406. (London and New York: Pergamon Press, Ltd., 1966.) 63s. net.

THIS book consists of a collection of problems on the differential equations arising in the mechanics of continuous media, in the vibrations of mechanical systems, in the theory of heat conduction and in magnetism and electricity. It includes problems on the use of curvilinear co-ordinates, Green's functions, conformal transformations, eigenfunction expansions and integral transforms. There is a short chapter on integral equations. Solutions to about one in seven of the problems are given. There are also hints for the solution of some of the others, and each problem has its answer printed immediately below it. At the beginning of each section there is a brief introduction to the general method involved in the following problems.

The easier parts of the book are of a standard appropriate to a first-year undergraduate course in applied mathematics or physics at a British university, but some of the problems reach a degree of complexity unlikely to be encountered in first degree work. The solutions provided are of adequate clarity, but the translation is very often clumsy and sometimes obscure.

It is difficult to see who will use the book. It cannot be used as a text-book; the introductory sections are too brief, and the number of solutions too small for this. Many of the existing text-books in this field already have adequate selections of problems. No doubt hard-pressed examiners will turn to it from time to time.

The book is well produced, and the price is reasonable. W. E. PARry

\section{Modern Methods of Chemical Analysis}

By J. A. Barnard and R. Chayen. Pp. xiii + 273. (Maidenhead and New York: McGraw-Hill Publishing Company, Ltd., 1965.) 42s. $6 d$.

THIs book is primarily for student readership and the subject matter derives from a second year course for chemical engineering undergraduates. There are six chapters-Volumetric Methods, Polarography, Spectroscopic Analysis, Mass Spectrometry, Radiochemical Methods, and Separation Techniques. Included in the text are 56 detailed experiments covering all the chapters with the exception of mass spectrometry. In their preface the authors state that the book will persuade the reader that "... many of the skills needed can bo fairly quickly acquired, and the basic theory readily understood". On the experimental side the claim is fully substantiated; the exercises are carefully chosen to illustrate the facets of the techniques described and they are within the senpe of a reasonably well equipped college laboratory. This part of the work can be recommended with confidence.

In general the basic principles are less well presented. One would like to have seen rather more emphasis on the scope and limitations of the techniques described to give the reader a true perspective of the factual material. The balance of theoretical material is occasionally uneven; in discussing ion exchange, for example, several pages are devoted to the synthesis of organic resins, but no mention is made of the experimentally important selectivity of the resins for ions of varying charge and size. 